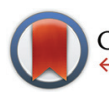

CrossMark \& click for updates

Cite this: Food Funct., 2016, 7, 4231

\title{
Food processing and structure impact the metabolizable energy of almonds $\uparrow t$
}

\author{
Sarah K. Gebauer, ${ }^{a}$ Janet A. Novotny, ${ }^{a}$ Gail M. Bornhorst ${ }^{\mathrm{b}}$ and David J. Baer*a
}

The measured metabolizable energy (ME) of whole almonds has been shown to be less than predicted by Atwater factors. However, data are lacking on the effects of processing (roasting, chopping or grinding) on the ME of almonds. A 5-period randomized, crossover study in healthy individuals $(n=18)$ was conducted to measure the ME of different forms of almonds (42 $\mathrm{g}$ per day), as part of a controlled diet: whole, natural almonds; whole, roasted almonds; chopped almonds; almond butter; and control $(0 \mathrm{~g}$ per day). After 9 days of adaptation to each diet, participants collected all urine and fecal samples for 9 days. Diets, urine, and feces were analyzed to determine ME. Fracture force and fracture properties of whole and chopped almonds were measured. Measured ME ( $\mathrm{kcal} \mathrm{g}^{-1}$ ) of whole natural almonds (4.42), whole roasted almonds (4.86), and chopped almonds (5.04) was significantly lower than predicted with Atwater factors $(P<0.001)$; ME of almond butter $\left(6.53 \mathrm{kcal} \mathrm{g}^{-1}\right)$ was similar to predicted $(P=0.08)$. The ME of whole roasted and chopped almonds was lower than almond butter $(P<0.0001)$. ME of whole natural almonds was lower than whole roasted almonds $(P<0.05)$. This may be due to lower hardness of whole roasted $(298 \pm 1.3 \mathrm{~N})$ compared to whole natural almonds ( $345 \pm 1.6 \mathrm{~N})(P<0.05)$, and to whole natural almonds fracturing into fewer, larger particles, thus inhibiting the release of lipids. Atwater factors overestimate the ME of whole (natural and roasted) and chopped almonds. The amount of calories absorbed from almonds is dependent on the form in which they are consumed.

Received 18th July 2016, Accepted 17th September 2016

DOI: 10.1039/c6fo01076h

www.rsc.org/foodfunction
Previous studies with nuts have demonstrated that food form impacts macronutrient absorption. Absorption of fat from whole nuts and peanuts is less than that for other forms of nuts, including butter, oil, and flour, ${ }^{10,11}$ suggesting that the food matrix impacts metabolizable energy (ME) of food. Recent research has focused on several aspects of the physiochemical nature of the almond seed matrix in order to understand the dynamics of food digestion and release of energy. Using in vitro digestion models, Grundy et al. have demonstrated that intact almond cell walls encapsulate lipid which prevents diffusion of lipase into the intracellular space and thus inhibits lipolysis. ${ }^{12}$ Unless these cell walls are disrupted, lipid digestion is limited. From in vitro duodenal digestion models, Grundy also has shown that particle size has an impact on lipid bioaccessibility. ${ }^{13}$ Despite the fact that roasting almonds results in smaller particles when masticated, ${ }^{14,15}$ in vitro digestion models (gastric and duodenal) do not show differences in lipid bioaccessibility. ${ }^{15}$ Nonetheless, the observed in vivo differences in lipemic response of different forms of almonds ${ }^{11,16}$ suggest that the ME of almonds processed by different methods may be different, which may impact the accurate labeling of food.

The Atwater general factors and Atwater specific factors, developed in the late 1800s and 1950s, respectively, are still the predominantly used methods to calculate the energy 
content of foods in nutrient databases and on food labels. We have previously shown that Atwater factors overestimate the measured ME of whole nuts (pistachios, almonds), and walnuts pieces, due to incomplete absorption of macronutrients. ${ }^{17-19}$ However, the measured ME of other forms of nuts is unknown. The objective of the present study was to determine the impact of food structure and processing (roasting, chopping or grinding) on the measured ME of almonds, within the context of a completely controlled diet.

\section{Materials \& methods}

\section{Study design}

The study was a randomized, crossover, controlled-feeding trial consisting of five 3-week diet periods, each separated by a 1-week break. Participants were fed the following controlled diets consisting of a base diet (typical American diet) and varying forms of almonds: whole, natural almonds $\left(42 \mathrm{~g} \mathrm{~d}^{-1}\right)$; whole, dry roasted almonds $\left(42 \mathrm{~g} \mathrm{~d}^{-1}\right)$; chopped almonds (dry roasted, $42 \mathrm{~g} \mathrm{~d}^{-1}$ ); almond butter (dry roasted, $42 \mathrm{~g} \mathrm{~d}^{-1}$ ), and control $\left(0 \mathrm{~g} \mathrm{~d}^{-1}\right)$. After 9 days of adaptation to each diet, participants collected all urine and fecal samples for 9 days. Study procedures were approved by the Institutional Review Board of the MedStar Health Research Institute, and were in compliance with the principles of the Declaration of Helsinki.

\section{Recruitment \& participant selection}

Participants were recruited from the Washington, DC metropolitan area and required to attend a study information meeting. At that meeting, details and requirements of the study were reviewed and interested individuals completed a study application, provided written informed consent, and were subsequently screened for the study. Screening was conducted following a 12-hour fast and included measurement of height, weight, and blood pressure; collection of blood for lipid profile, comprehensive metabolic panel, complete blood count, thyroid stimulating hormone, and urine for urinalysis; and collection of health history information. Eligibility was determined by a study physician or nurse practitioner. Participants were required to meet the following criteria: age 25-75 years, body mass index (BMI) between 20

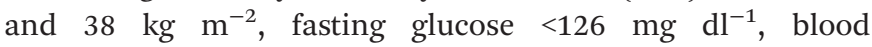
pressure $<160 / 100 \mathrm{~mm} \mathrm{Hg}$, fasting total blood cholesterol

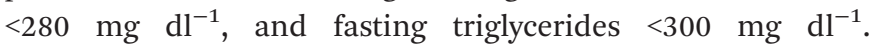
Participants were excluded if they had any of the following characteristics or conditions: presence of type 2 diabetes, kidney disease, liver disease, gout, hyperthyroidism, untreated or unstable hypothyroidism, certain cancers, gastrointestinal disease, pancreatic disease, and other metabolic diseases or malabsorption syndromes; pregnant or lactating women, or women who gave birth during previous 12 months; history of bariatric or certain other surgeries related to weight control; use of tobacco products or smokers (during previous 6 months); history of eating disorders or other dietary patterns not consistent with the dietary intervention, including vegetarians; loss of $10 \%$ of body weight during previous 12 months; or allergy to almonds or other nuts.

Study participants were randomized to a treatment sequence consisting of each of the 5 diet periods. The randomization scheme was created using a permutation calculator and random number generator. There were 18 sequences that were selected and checked for balance of treatment by period.

\section{Controlled diet}

Participants were fed a completely controlled diet for each of the five 3-week diet periods. Participants came in to the Human Studies Facility at the USDA Beltsville Human Nutrition Research Center (BHNRC) in Beltsville, MD for both breakfast and dinner, Monday through Friday, where meals were administered under the supervision of study personnel. Lunch and weekend meals were packed for offsite consumption. Participants were instructed to consume all of the foods provided to them and to not consume any outside food during the 5 diet periods. Outside beverages that were permitted included unlimited water and unlimited calorie free lemonade and diet soda (in the varieties provided). Coffee and tea were limited to no more than 2 cups per day, in the varieties provided. Consumption of alcoholic beverages was not permitted during the diet periods.

Diets were designed by a study dietitian using a 7-day menu rotation. The control diet consisted of the base diet, designed as a typical American diet (31\% fat, 16\% protein, 53\% carbohydrate), and $0 \mathrm{~g} \mathrm{~d}^{-1}$ of almonds. All foods were identical between the control and almond diets, except for the almonds. This was achieved by proportionately reducing the amount of every food on the base diet to allow for the isocaloric inclusion of $42 \mathrm{~g} \mathrm{~d}^{-1}$ almonds.

All of the almonds (nonpareil variety) fed in the study were provided by the Almond Board of California and originated from the same lot (purchased from Hughson Nut, Inc.). The only difference in the almonds across treatments was whether they remained as whole natural almonds or whether they were dry roasted (154-157 $\mathrm{C}, 9$ min roasting time), and either packaged as whole roasted almonds, chopped (particle sizes of $8.7 \& 3.2 \mathrm{~mm}$ corresponding to industry standard of medium $22 / 8$ ), or ground into almond butter (ground to smooth consistency by a commercial processor, Maisie Jane's California Products, Inc., with no additives). The dose of $42 \mathrm{~g}$ (1.5 oz) was selected based on the U.S. Food \& Drug Administration qualified health claim for nuts. Half of the daily dose of almonds was included at breakfast and half of the dose was included at dinner, so that nuts were consumed while participants were at the facility.

Participants were assigned to an individual calorie level using the Harris Benedict equation, based on an age, height, weight, and activity level. Body weight was measured daily, Monday through Friday, and was closely monitored throughout the intervention. Adjustments in calorie level were made 
in $200 \mathrm{kcal}$ increments if participants exhibited changes in body weight. Adherence to the diets was assessed by daily interaction with participants, monitoring of body weight, and review of daily questionnaires. Daily questionnaires collected information regarding general health, medications, and exercise; amounts of approved beverages consumed (diet soda, calorie free lemonade, coffee, and tea); documentation of any non-study foods; and verification that all study foods were consumed.

\section{Sample collection \& analysis}

Diet composites, consisting of a complete 7-day menu cycle, were created during each diet period, as previously described..$^{20}$ Briefly, foods were prepared as typically consumed (heated, toasted, etc.) and blended in a blender. Diet composites were frozen at $-80 \mathrm{C}$ and then freeze dried for chemical analysis.

Urine was collected in $24 \mathrm{~h}$ cycles for 7 days of each diet period during which participants were instructed to collect all urine samples. Participants were provided daily collection supplies, including a $4 \mathrm{~L}$ container with boric acid (10 g), an overflow container if needed, and a collection form to record dates/times of collection, any missed samples, and use of medication.

Participants were administered a capsule containing Brilliant Blue to mark the start of the fecal collections. Supplies for fecal collections included a large Styrofoam cooler with dry ice, plastic collection bags, a collection apparatus, and a gym bag to transport samples. Participants were instructed to collect all fecal samples and store them on dry ice until their next visit to the BHNRC. A second capsule of Brilliant Blue was given after 7 days of collection and participants continued collecting until instructed by the study staff to stop. Appearance of the second marker in the feces indicated the end of the collection phase. All samples collected between the appearance of the first and second marker were included for analysis. Daily collection forms were completed with date and time of sample and whether any samples were missed.

Details of chemical analysis have been previously published. ${ }^{18}$ Briefly, adiabatic bomb calorimetry (Parr Instrument Company; Moline, IL) was used to measure energy of diet, feces, and urine. Samples were analyzed in duplicate. ME was determined by the methods of Novotny et al., ${ }^{18}$ using the following equation:

$$
\begin{aligned}
& \mathrm{ME}_{\text {Almond }\left(\mathrm{kcal} \mathrm{g}^{-1}\right)} \\
& =\frac{\left[\mathrm{MEI}_{\text {Almond diet }}\right]-\left[\left(\mathrm{GEI}_{\text {Almond diet }}-\mathrm{GEI}_{\text {Almond }}\right) \times\left(\frac{\mathrm{MEI}_{\text {controldiet }}}{\mathrm{GEI}_{\text {controldiet }}}\right)\right]}{\Delta \text { Almond Intake }}
\end{aligned}
$$

where GEI is the gross energy intake for a given diet or food item ( $\mathrm{kcal} \mathrm{d}^{-1}$ ), MEI is the metabolizable energy intake for a given diet $\left(\mathrm{kcal} \mathrm{d}^{-1}\right)$, and $\Delta$ Almond Intake is the difference between the almond intake on the two diets (which was equivalent to the mass of almond incorporated into the almondcontaining diet), base diet $=$ control diet.

\section{Almond physical property determination}

Fracture force of whole almonds. Three-point bending was used to quantify the fracture force of whole natural $(n=25)$ and roasted almond $(n=25)$ samples. Each almond kernel was placed horizontally between supports with a length span of $10 \mathrm{~mm}$. The kernels were compressed at $1 \mathrm{~mm} \mathrm{~s}^{-1}$ with a $3 \mathrm{~mm}$ blade until fracture. The fracture force $(N)$ was quantified as the load at failure, or the maximum force during compression $(N)$.

Fracture properties. Fracture properties of whole natural, whole roasted, and chopped roasted almonds were quantified using the method by Varela $e t$ al. ${ }^{21}$ Briefly, a TA.XT2 Texture Analyzer (Texture Technologies Corp., Scarsdale, NY) with a $45 \mathrm{~mm}$ cylindrical plunger was used for compression tests $(n=$ 25 for each almond type). One whole almond or $1 \mathrm{~g}$ chopped almonds (approximately equivalent in mass to one whole almond) was compressed at $30 \mathrm{~mm} \mathrm{~s}^{-1}$ to $71 \%$ strain. The hardness was quantified as the maximum force during compression $(N)$. These conditions were previously determined to effectively characterize the fracture of almonds during chewing. ${ }^{21}$ After compression, sample fragments were dispersed on a black background and photographed with a Canon EOS Rebel SL1 digital camera (Canon USA, Inc., San Jose, CA). Image processing was completed using Image J (U. S. National Institutes of Health, Bethesda, MD). Images were converted to 8 bit and a threshold was applied prior to conversion to binary images. The area of each particle $\left(\mathrm{mm}^{2}\right)$ and the total number of particle fragments in each image was determined using the Analyze Particles function. The distribution of particle area was determined based on the individual particle areas for each image and analyzed as previously described. ${ }^{22}$ Briefly, the cumulative area percentage was fit to the Rosin-Rammler distribution: ${ }^{23}$

$$
C_{\text {area }}=1-\mathrm{e}^{-\left(X / X_{50}\right)^{b} \cdot \ln 2}
$$

where $C_{\text {area }}$ is the cumulative area percentage of particles having area $\times\left(\mathrm{mm}^{2}\right), x_{50}$ is the median particle area $\left(\mathrm{mm}^{2}\right)$, and $b$ is a constant (dimensionless) that represents the broadness of the distribution function (larger $b$ values represent a more narrow distribution). The $x_{50}$ and $b$ values were determined using non-linear regression in MATLAB R2015a (MathWorks, Natick, MA, U.S.A). The Rosin-Rammler distribution has been previously shown to provide a good fit to particle breakdown during mastication ${ }^{24-26}$ and during gastric digestion. ${ }^{22}$

\section{Particle size distribution of almond butter}

Particle size distribution analysis of almond butter was completed using a Mastersizer 2000 (Malvern Instruments Ltd, Malvern, UK), which uses static light scattering to measure the particle size distribution in an emulsion or suspension. The refractive index used was 1.59 . To accurately measure the almond particle fragments in the almond butter, isopropanol was used as a dispersant, and samples of almond butter were mixed with isopropanol prior to loading into the measurement 
chamber (10-15\% obscuration) at a pump rate of $2500 \mathrm{rpm}$. Each sample was measured ten times. Six measurements of four jars of almond butter were completed, resulting in a total of 24 measurements.

\section{Statistical analysis}

The ME values of different forms of almonds were compared using a mixed model analysis (SAS version 9.3, SAS Institute Inc., Cary, NC) with contrast statements for the following a priori defined comparisons: whole natural almonds versus whole roasted almonds; whole roasted almonds versus chopped almonds (roasted); whole roasted almonds versus almond butter (roasted); and chopped almonds (roasted) versus almond butter (roasted). The model included subject as a random term, and effects of treatment, period, and interaction of treatment $\times$ period were tested. A paired $t$-test was used to compare the measured ME and predicted ME for each of the almond forms. One-way ANOVA using the Tukey Studentized Range (HSD) test was used to analyze differences between natural and roasted almond fracture force, and to analyze differences between whole natural, whole roasted, and roasted chopped fracture properties. Significance was determined based on $P<0.05$. Values are expressed as mean \pm SEM.

\section{Results}

Baseline characteristics of the participants $(n=18 ; 10 \mathrm{M}, 8 \mathrm{~F})$ were as follows: age $=56.7 \pm 2.4$ years; height $=170.2 \pm 2.1 \mathrm{~cm}$; and body weight $=88.6 \pm 5.6 \mathrm{~kg}$. Participants were adherent to the protocol, as indicated by daily questionnaires, collection forms, and daily weekday interactions with participants during breakfast and dinner. The macronutrient composition of the base diet and 4 almond treatments is presented in Table 1. The base diet provided $16 \%, 25 \%$, and $59 \%$ of energy from protein, fat and carbohydrate, respectively, and the diets with almonds provided $15 \%, 30 \%$, and $55 \%$ of energy from protein, fat, and carbohydrate, respectively.

Fracture force of almonds was significantly influenced by almond type $(P<0.0001)$. The average fracture force was significantly greater for natural almonds $(70.0 \pm 2.9 \mathrm{~N})$ compared to roasted almonds $(52.0 \pm 2.2 \mathrm{~N})(P<0.05$, Table 2$)$. Hardness of whole natural, whole roasted and roasted chopped almonds was significantly influenced by almond type $(P<0.01)$. Whole natural almonds had a greater hardness $(345 \pm 1.6 \mathrm{~N})$
Table 2 Fracture force and hardness for almond samples ${ }^{a}$

\begin{tabular}{lll}
\hline Almond type & Fracture force $(\mathrm{N})$ & Hardness $(\mathrm{N})$ \\
\hline Whole, natural almonds & $70.0 \pm 2.9^{\mathrm{a}}$ & $345 \pm 1.6^{\mathrm{a}}$ \\
Whole, roasted almonds & $52.0 \pm 2.2^{\mathrm{b}}$ & $298 \pm 1.3^{\mathrm{b}}$ \\
Chopped, roasted almonds & - & $310 \pm 1.4^{\mathrm{ab}}$
\end{tabular}

${ }^{a}$ Fracture force was quantified by the three-point bending test on a whole almond kernel, and could not be completed on chopped samples. Hardness was quantified by uniaxial compression of one almond kernel or $1 \mathrm{~g}$ of chopped almonds. One-way ANOVA using the Tukey Studentized Range (HSD) test was used to analyze differences between treatment almonds. Values are shown as mean \pm standard error $(n=25)$. Values within each column with different letters are significantly different $(P<0.05)$.

compared to whole roasted almonds $(298 \pm 1.3 \mathrm{~N})$ (Table 2). Chopped roasted almonds had an intermediate hardness $(310 \pm 1.4 \mathrm{~N})$, which was not different from either whole natural or whole roasted almonds (Table 2).

The fracture properties of whole natural, whole roasted, and chopped roasted almonds are shown in Table 3, and example images of one almond (or $1 \mathrm{~g}$ chopped almonds) after compression are shown in Fig. 1. The Rosin-Rammler model provided a good fit to the experimental data $\left(R^{2}=0.99-1.00\right)$. The $x_{50}, b$, and number of particles per image were all influenced by almond type $(P<0.001)$. Whole natural almonds had a greater $x_{50}$ and $b$ value, but a lower number of particles per image compared to whole roasted almonds $(P<0.05)$. This indicates that as the whole natural almonds were fractured, they broke into fewer, larger pieces compared to whole roasted almonds. The chopped roasted almonds had a larger median particle area $\left(x_{50}\right)$ but a fewer number of particles per image compared to the whole roasted almonds $(P<0.05)$. The particle size distribution of almond butter (as consumed) is shown in Fig. 2. The median particle diameter (d50) was $11.0 \pm 0.4 \mu \mathrm{m}$. The $90^{\text {th }}$ percentile particle diameter $(d 90)$ was $170.4 \pm 24.1 \mu \mathrm{m}$.

The measured ME of whole natural almonds was lower than whole roasted almonds $(P<0.05)$ (Table 4$)$. When comparing the different forms of roasted almonds, the ME of whole and chopped almonds was lower than that of almond butter $(P<0.0001)$. The ME of whole roasted almonds was not statistically different from chopped roasted almonds $(P>0.05)$.

Based on the chemical analysis of each almond treatment (Table 1), the estimated ME $\left(\mathrm{kcal} \mathrm{g}^{-1}\right)$, calculated with Atwater

Table 1 Chemical analysis of the base diet and treatment almonds (g per $100 \mathrm{~g}$ dry weight) ${ }^{a}$

\begin{tabular}{|c|c|c|c|c|c|}
\hline & Base diet & $\begin{array}{l}\text { Whole, natural } \\
\text { almonds }\end{array}$ & $\begin{array}{l}\text { Whole, } \\
\text { roasted almonds }\end{array}$ & $\begin{array}{l}\text { Chopped, } \\
\text { roasted almonds }\end{array}$ & $\begin{array}{l}\text { Almond butter } \\
\text { (from roasted almonds) }\end{array}$ \\
\hline Protein $^{b}$ & $20.4 \pm 0.2$ & $20.7 \pm 0.1$ & $21.8 \pm 0.1$ & $20.8 \pm 0.1$ & $19.6 \pm 0.1$ \\
\hline Lipid & $14.4 \pm 0.2$ & $57.2 \pm 0.7$ & $55.6 \pm 0.3$ & $54.5 \pm 0.7$ & $56.1 \pm 0.5$ \\
\hline Ash & $3.68 \pm 0.10$ & $3.12 \pm 0.05$ & $3.07 \pm 0.09$ & $2.91 \pm 0.13$ & $2.92 \pm 0.11$ \\
\hline Carbohydrate $^{c}$ & 61.5 & 19.0 & 19.5 & 21.8 & 21.4 \\
\hline
\end{tabular}

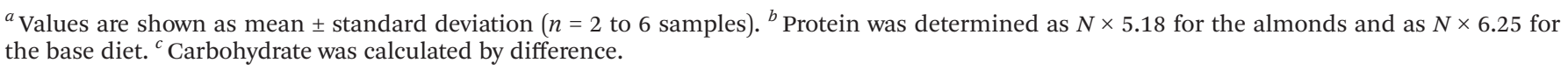


Table 3 Fracture properties of almond samples from image analysis ${ }^{a}$

\begin{tabular}{lllr}
\hline Almond type & $x_{50}\left(\mathrm{~mm}^{2}\right)$ & $b$ (dimensionless) & $\begin{array}{l}\text { Number of } \\
\text { particles/image }\end{array}$ \\
\hline Whole, natural almonds & $27.6 \pm 1.7^{\mathrm{a}}$ & $1.1 \pm 0.10^{\mathrm{a}}$ & $137 \pm 11^{\mathrm{c}}$ \\
Whole, roasted almonds & $13.7 \pm 0.4^{\mathrm{c}}$ & $0.9 \pm 0.05^{\mathrm{a}}$ & $339 \pm 10^{\mathrm{a}}$ \\
Chopped, roasted almonds & $17.5 \pm 0.5^{\mathrm{b}}$ & $1.1 \pm 0.08^{\mathrm{a}}$ & $185 \pm 8^{\mathrm{b}}$
\end{tabular}

${ }^{a}$ Values represent mean \pm standard error $(n=25)$. The $R^{2}$ value represents the average goodness of fit of the Rosin-Rammler distribution to the experimental data sets. One-way ANOVA using the Tukey Studentized Range (HSD) test was used to analyze differences between treatment almonds. Values within each column with different letters are statistically different $(P<0.05)$.

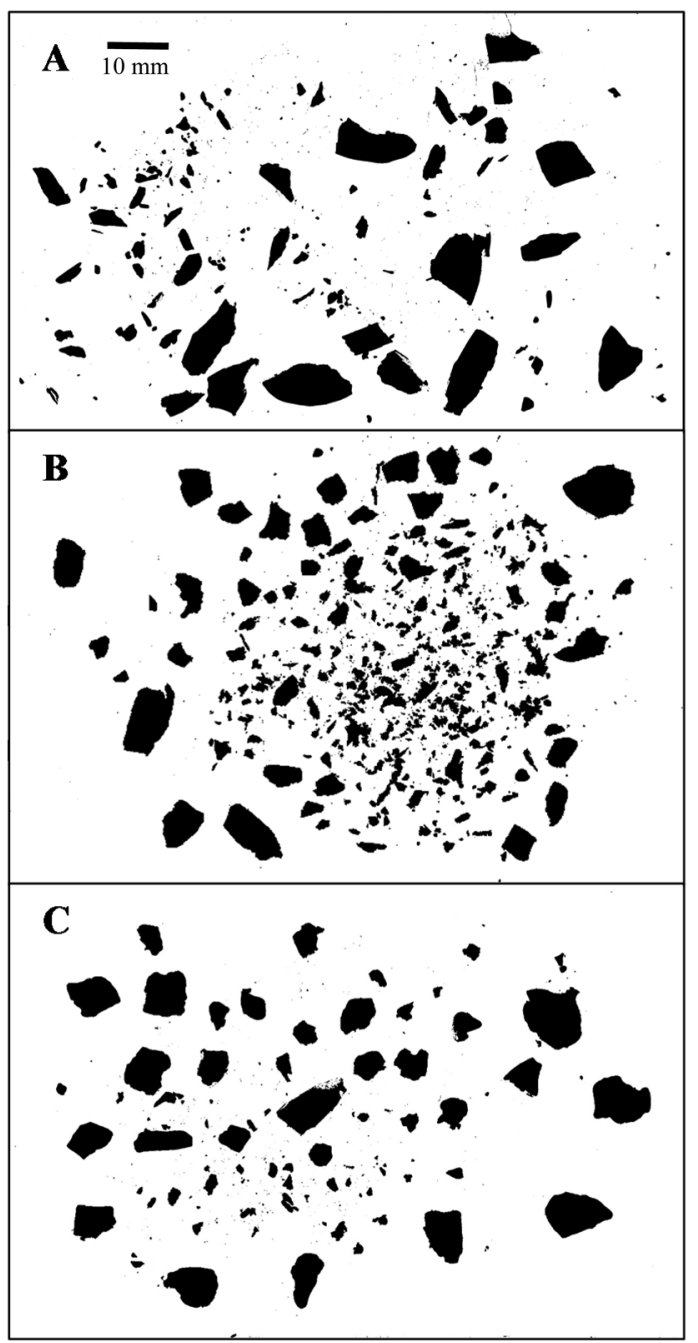

Fig. 1 Example binary images from the fracture of $(A)$ one whole natural almond, (B) one whole roasted almond, or (C) $1 \mathrm{~g}$ chopped roasted almonds, after compression at $30 \mathrm{~mm} \mathrm{~s}^{-1}$ to $71 \%$ strain.

general factors, values of the energy content of macronutrients based on general values for heats of combustion and digestibility, of whole natural almonds, whole roasted almonds, chopped almonds, and almond butter was 6.34, 6.44, 6.47, and 6.62, respectively. When using Atwater specific factors, values of the energy content of macronutrients based on heats of combustion and digestibility of different classes of foods,

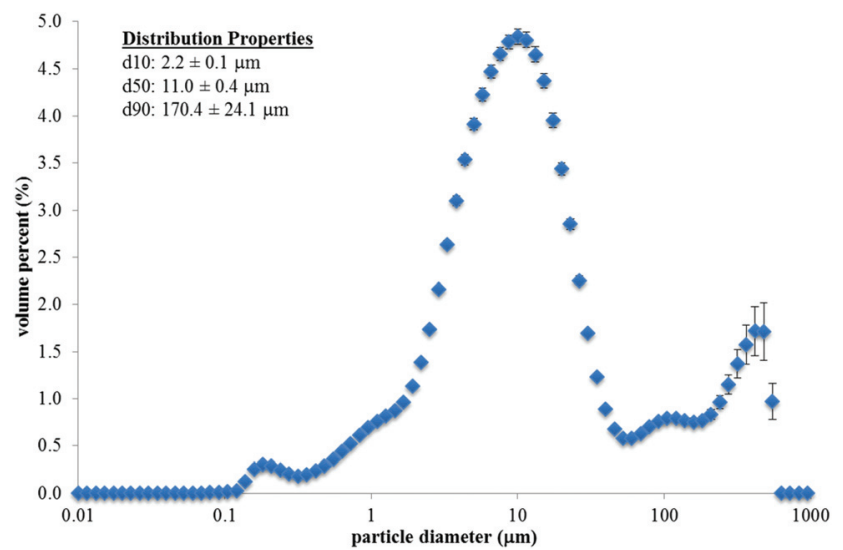

Fig. 2 Average particle size distribution for almond butter $(n=24)$. Errors bars represent the standard error. The average distribution properties ( $d 10$ - 10th percentile diameter; $d 50$ - 50th percentile diameter; and $d 90-90$ th percentile diameter) are given in the figure.

the estimated ME (kcal g ${ }^{-1}$ ) was 5.91, 6.01, 6.04, and 6.18, respectively. The measured $\mathrm{ME}\left(\mathrm{kcal} \mathrm{g}^{-1}\right)$ for whole natural almonds (4.42), whole roasted almonds (4.86), and chopped almonds (5.04), was significantly lower than that estimated by Atwater general or specific factors $(P<0.001$; Table 4$)$. The Atwater general factors overestimated ME by a greater extent than Atwater specific factors. The percent difference between the measured $\mathrm{ME}$ and the estimated $\mathrm{ME}$ value using the Atwater specific factors was $-25 \%,-19 \%$, and $-17 \%$, respectively for the whole natural almonds, whole roasted almonds, and chopped roasted almonds. The measured ME of almond butter $\left(6.53 \mathrm{kcal} \mathrm{g}^{-1}\right)$ was similar to that predicted when using Atwater general or specific factors ( $P>0.05$ for both).

\section{Discussion}

Overestimation of the ME of nuts may explain, in part, results from epidemiological and clinical studies that show that individuals who consume nuts have a lower body weight, ${ }^{27,28}$ are less likely to gain weight over time, ${ }^{6,29}$ and lose more weight on a calorie restricted diet, ${ }^{7}$ compared to those who do not consume nuts. There are numerous potential mechanisms, related to the unique nutrient profile of nuts, which may be contributing to their effects on body weight. ${ }^{30}$ Nuts are low in 
Table 4 Metabolizable energy $\left(\mathrm{kcal} \mathrm{g}^{-1}\right)$ of different forms of almonds as part of a controlled diet

\begin{tabular}{|c|c|c|c|}
\hline Almond type & $\begin{array}{l}\text { Measured } \\
\mathrm{ME}^{a}\end{array}$ & $\begin{array}{l}\text { Estimated ME using } \\
\text { atwater general factors }\end{array}$ & $\begin{array}{l}\text { Estimated ME using } \\
\text { atwater specific factors }\end{array}$ \\
\hline Whole, natural almonds & $4.42 \pm 0.24^{\mathrm{a}}$ & $6.34^{c}$ & $5.91^{c}$ \\
\hline Whole, roasted almonds & $4.86 \pm 0.24^{b}$ & $6.44^{c}$ & $6.01^{c}$ \\
\hline Chopped, roasted almonds & $5.04 \pm 0.20^{\mathrm{b}}$ & $6.47^{c}$ & $6.04^{c}$ \\
\hline Almond butter & $6.53 \pm 0.19^{c}$ & 6.62 & 6.18 \\
\hline
\end{tabular}

Metabolizable energy, ME. ${ }^{a}$ Values presented are mean \pm standard error $(n=18)$. Values within each column with different letters are statistically different $(P<0.05)$. Mixed model analysis was used to compare ME of different forms of almonds, using contrast statements for the following a priori defined comparisons: whole natural almonds versus whole roasted almonds; whole roasted almonds versus chopped almonds (roasted); whole roasted almonds versus almond butter (roasted); and chopped almonds (roasted) versus almond butter (roasted). ${ }^{b}$ Differences in measured metabolizable energy and estimated metabolizable energy were determined by paired $t$-tests. Estimated metabolizable energy using Atwater General Factors represents the calculated metabolizable energy based on Atwater general factors and the measured macronutrient composition of each almond form. Estimated metabolizable energy using Atwater specific factors represents the calculated metabolizable energy based on Atwater specific factors and the measured macronutrient composition of each almond form. ${ }^{c}$ Statistically different compared with measured metabolizable energy $(P<0.05)$.

saturated fat, and high in unsaturated fat, plant protein, and fiber, as well as numerous vitamins, minerals and other bioactive compounds. In randomized controlled trials, where diets are tightly controlled and not self-selected, incomplete mastication leads to an increase in macronutrient loss in the feces, which results in lower energy available to the body. In addition to incomplete absorption, in free-living studies where diets are self-selected, nut consumption leads to increases in protein and fiber intake, which results in increased satiety/ decreased hunger and a reduction in energy intake.

As is common with all plant cells, the energy containing macronutrients contained in each almond cell is surrounded by a cell wall. Disruption of the cell wall can occur by mechanical means, either during mastication, processing, chopping or grinding, or by bacterial fermentation in the colon (after the site of absorption). Previous studies with almonds have shown that incomplete rupturing of cell walls during mastication of almond seed tissue results in a large proportion of intact cells. ${ }^{31}$ The energy containing macronutrients encapsulated in these intact cells remain inaccessible to digestive enzymes, and are excreted in the feces, such that they are not absorbed. Studies have demonstrated that particle size, an indicator of the proportion of unruptured cells, is related to the bioaccessibility of the macronutrients contained in almonds. ${ }^{14,16}$ Particle size of almonds decreases as the degree of mastication increases (due to greater cell wall disruption), resulting in less fecal fat excretion and higher energy absorption.

Processing of nuts, such as roasting, chopping, and grinding, impacts mastication, particle size, and lipid bioaccessibility; $^{11,14,32}$ however, the ME of different forms of almonds has not been previously determined. In the present study, the dry roasting of whole almonds resulted in a higher ME compared with natural almonds. Dehydration during the roasting process causes almond tissue to be more brittle, leading to a higher proportion of smaller particles (and lower proportion of large particles) and increases in energy absorption. ${ }^{14}$

In the present study, whole natural almonds had a greater fracture force and greater hardness compared to whole roasted almonds. Although the fracture force (52 to $70 \mathrm{~N}$ ) for either type of almonds is much less than the average bite force exerted by the teeth in adult humans ( $630 \mathrm{~N}$ for males and 424 $\mathrm{N}$ for females), ${ }^{33}$ it may play a role in the fracture properties and resulting particle size distribution during chewing.

Fracture properties of whole natural and roasted almonds were determined after compression of a single almond kernel, as this method has been shown to provide similar results to the particle size after in vivo mastication of almonds. ${ }^{21}$ After fracture, whole roasted almonds had a greater number of particles with a smaller median particle area (Table 3, Fig. 1) compared to whole roasted almonds. This may indicate that during mastication, whole roasted almonds are broken down to a greater degree. As previously reported, smaller particles result in greater lipid release from the almond cell walls. ${ }^{16,34}$ Since the whole roasted almonds had smaller particles, a greater amount of lipids may have been released, resulting in greater ME compared to whole natural almonds.

The ME of whole roasted and chopped almonds was lower than almond butter, which is likely due to extensive cell wall disruption during the grinding of almonds into butter. The median particle size of the almond butter was $11 \mu \mathrm{m}$. Since the almond butter already had a large particle size reduction during grinding, there was little additional breakdown required during mastication and digestion. This extensive cell wall disruption and small particle size may have allowed more energy to be released from the cells and absorbed by the body compared to the chopped and whole almonds, resulting in the higher observed ME value. The ME of almond butter was similar to what is predicted by the Atwater factors.

The ME of whole, roasted almonds was not statistically different than chopped almonds. The median particle area after fracture was in a similar range for whole and chopped roasted almonds, although the values were significantly different (13.7 vs. $17.5 \mathrm{~mm}^{2}$ ). However, both of these values were significantly lower than the median particle area for whole natural almonds $\left(27.6 \mathrm{~mm}^{2}\right)$. This may indicate that during roasting, regardless of whether the almonds are whole or chopped, particles break down to a similar degree, which results in a similar ME value. 
Variability of ME ranged from $2.84 \mathrm{kcal} \mathrm{g}^{-1}$ to $7.66 \mathrm{kcal} \mathrm{g}^{-1}$ across the almond forms. Individual differences in mastication patterns likely contribute to the variability in ME. Instruction was not provided with regards to chewing so that the mastication of the different almond forms was representative of typical consumption. Variability in individual responses differed based on almond form (data not shown), suggesting that differences in mastication patterns have less of an impact on ME when almonds are ground into butter than when they are consumed whole (i.e., cell walls are already ruptured during grinding and energy is more available regardless of differences in mastication). Individual differences in intestinal microbiota also may contribute to variability of ME. Future studies are warranted to determine whether differences in microbiota explain differences in ME across individuals, which could have broader implications with regards to energy intake and body weight of individuals.

\section{Conclusions}

The results from the present study demonstrate that processing and structure impact the ME of almonds. The Atwater specific factors overestimate the ME of whole natural, whole roasted, and chopped roasted almonds by $25 \%, 19 \%$, and $17 \%$, respectively. These differences are likely related to the hardness and fracture properties of the almond matrix and the degree of food structural breakdown during processing and mastication. Additional studies are warranted to further investigate the impact of food matrix and processing on the metabolizable energy of foods.

\section{Conflict of interest}

There are no conflicts of interest to declare.

\section{Acknowledgements}

Support was provided by the USDA Agricultural Research Service and the Almond Board of California. The authors would like to acknowledge Patrick Sullivan and the staff of the Human Studies Facility (BHNRC) for preparation and administration of the diets, and Theresa Henderson and the staff of the Food Components \& Health Lab (BHNRC) for the processing and analysis of samples.

\section{References}

1 L. C. Del Gobbo, M. C. Falk, R. Feldman, K. Lewis and D. Mozaffarian, Effects of tree nuts on blood lipids, apolipoproteins, and blood pressure: systematic review, meta-analysis, and dose-response of 61 controlled intervention trials, Am. J. Clin. Nutr., 2015, 102, 1347-1356.
2 G. Grosso, J. Yang, S. Marventano, A. Micek, F. Galvano and S. N. Kales, Nut consumption on all-cause, cardiovascular, and cancer mortality risk: a systematic review and meta-analysis of epidemiologic studies, Am. J. Clin. Nutr., 2015, 101, 783-793.

3 E. Ros, Nuts and CVD, Br. J. Nutr., 2015, 113(Suppl 2), S111-S120.

4 M. Falasca, I. Casari and T. Maffucci, Cancer chemoprevention with nuts, J. Natl. Cancer Inst., 2014, 106.

5 M. Bes-Rastrollo, J. Sabate, E. Gomez-Gracia, A. Alonso, J. A. Martinez and M. A. Martinez-Gonzalez, Nut consumption and weight gain in a Mediterranean cohort: The SUN study, Obesity, 2007, 15, 107-116.

6 D. Mozaffarian, T. Hao, E. B. Rimm, W. C. Willett and F. B. Hu, Changes in diet and lifestyle and long-term weight gain in women and men, N. Engl. J. Med., 2011, 364, 2392-2404.

7 M. A. Wien, J. M. Sabate, D. N. Ikle, S. E. Cole and F. R. Kandeel, Almonds vs complex carbohydrates in a weight reduction program, Int. J. Obes. Relat. Metab. Disord., 2003, 27, 1365-1372.

8 C. E. O'Neil, V. L. Fulgoni 3rd and T. A. Nicklas, Tree Nut consumption is associated with better adiposity measures and cardiovascular and metabolic syndrome health risk factors in U.S. Adults: NHANES 2005-2010, Nutr. J., 2015, 14, 64 .

9 C. E. O’Neil, T. A. Nicklas and V. L. Fulgoni 3rd, Tree nut consumption is associated with better nutrient adequacy and diet quality in adults: National Health and Nutrition Examination Survey 2005-2010, Nutrients, 2015, 7, 595-607.

10 A. S. Levine and S. E. Silvis, Absorption of whole peanuts, peanut oil, and peanut butter, N. Engl. J. Med., 1980, 303, 917-918.

11 S. E. Berry, E. A. Tydeman, H. B. Lewis, R. Phalora, J. Rosborough, D. R. Picout and P. R. Ellis, Manipulation of lipid bioaccessibility of almond seeds influences postprandial lipemia in healthy human subjects, Am. J. Clin. Nutr., 2008, 88, 922-929.

12 M. M. Grundy, F. Carriere, A. R. Mackie, D. A. Gray, P. J. Butterworth and P. R. Ellis, The role of plant cell wall encapsulation and porosity in regulating lipolysis during the digestion of almond seeds, Food Funct., 2015, 7, 69-78.

13 M. M. Grundy, P. J. Wilde, P. J. Butterworth, R. Gray and P. R. Ellis, Impact of cell wall encapsulation of almonds on in vitro duodenal lipolysis, Food Chem., 2015, 185, 405-412.

14 M. M. Grundy, T. Grassby, G. Mandalari, K. W. Waldron, P. J. Butterworth, S. E. Berry and P. R. Ellis, Effect of mastication on lipid bioaccessibility of almonds in a randomized human study and its implications for digestion kinetics, metabolizable energy, and postprandial lipemia, Am. J. Clin. Nutr., 2015, 101, 25-33.

15 G. Mandalari, M. M. Grundy, T. Grassby, M. L. Parker, K. L. Cross, S. Chessa, C. Bisignano, D. Barreca, E. Bellocco, G. Lagana, P. J. Butterworth, R. M. Faulks, P. J. Wilde, P. R. Ellis and K. W. Waldron, The effects of processing and mastication on almond lipid bioaccessibil- 
ity using novel methods of in vitro digestion modelling and micro-structural analysis, Br. J. Nutr., 2014, 112, 15211529.

16 B. A. Cassady, J. H. Hollis, A. D. Fulford, R. V. Considine and R. D. Mattes, Mastication of almonds: effects of lipid bioaccessibility, appetite, and hormone response, Am. J. Clin. Nutr., 2009, 89, 794-800.

17 D. J. Baer, S. K. Gebauer and J. A. Novotny, Measured energy value of pistachios in the human diet, Br. J. Nutr., 2012, 107, 120-125.

18 J. A. Novotny, S. K. Gebauer and D. J. Baer, Discrepancy between the Atwater factor predicted and empirically measured energy values of almonds in human diets, Am. J. Clin. Nutr., 2012, 96, 296-301.

19 D. J. Baer, S. K. Gebauer and J. A. Novotny, Walnuts Consumed by Healthy Adults Provide Less Available Energy than Predicted by the Atwater Factors, J. Nutr., 2016, 146, 1-8.

20 S. C. Chen, J. T. Judd, M. Kramer, G. W. Meijer, B. A. Clevidence and D. J. Baer, Phytosterol intake and dietary fat reduction are independent and additive in their ability to reduce plasma LDL cholesterol, Lipids, 2009, 44, 273-281.

21 P. Varela, A. Salvador and S. Fiszman, On the assessment of fracture in brittle foods: The case of roasted almonds, Food Res. Int., 2008, 41, 544-551.

22 G. M. Bornhorst, K. Kostlan and R. P. Singh, Particle Size Distribution of Brown and White Rice during Gastric Digestion Measured by Image Analysis, J. Food Sci., 2013, 78, E1383-E1391.

23 P. Rosin and E. Rammler, Gesetzmassigkeiten in der Kornzusammensetzung des Zementes, Zement, 1933, 31, 427-433.

24 S. C. Hutchings, K. D. Foster, J. E. Bronlund, R. G. Lentle, J. R. Jones and M. P. Morgenstern, Mastication of heterogeneous foods: Peanuts inside two different food matrices, Food Qual. Pref., 2011, 22, 332-339.
25 A. van der Bilt, L. W. Olthoff, H. W. van der Glas, K. van der Weelen and F. Bosman, A mathematical description of the comminution of food during mastication in man, Arch. Oral Biol., 1987, 32, 579-586.

26 L. W. Olthoff, A. Van Der Bilt, F. Bosman and H. H. Kleizen, Distribution of particle sizes in food comminuted by human mastication, Arch. Oral Biol., 1984, 29, 899-903.

27 J. Sabate, Nut consumption and body weight, Am. J. Clin. Nutr., 2003, 78, 647S-650S.

28 R. C. Brown, S. L. Tey, A. R. Gray, A. Chisholm, C. Smith, E. Fleming and W. Parnell, Association of Nut Consumption with Cardiometabolic Risk Factors in the 2008/2009 New Zealand Adult Nutrition Survey, Nutrients, 2015, 7, 7523-7542.

29 M. Bes-Rastrollo, N. M. Wedick, M. A. Martinez-Gonzalez, T. Y. Li, L. Sampson and F. B. Hu, Prospective study of nut consumption, long-term weight change, and obesity risk in women, Am. J. Clin. Nutr., 2009, 89, 1913-1919.

30 C. L. Jackson and F. B. Hu, Long-term associations of nut consumption with body weight and obesity, Am. J. Clin. Nutr., 2014, 100(Suppl 1), 408S-411S.

31 P. R. Ellis, C. W. Kendall, Y. Ren, C. Parker, J. F. Pacy, K. W. Waldron and D. J. Jenkins, Role of cell walls in the bioaccessibility of lipids in almond seeds, Am. J. Clin. Nutr., 2004, 80, 604-613.

32 F. McKiernan and R. D. Mattes, Effects of Peanut Processing on Masticatory Performance during Variable Appetitive States, J. Nutr. Metab., 2010, 2010.

33 R. A. M. de Abreu, M. D. Pereira, F. Furtado, G. P. R. Prado, W. Mestriner Jr. and L. M. Ferreira, Masticatory efficiency and bite force in individuals with normal occlusion, Arch. Oral Biol., 2014, 59, 1065-1074.

34 T. Grassby, D. R. Picout, G. Mandalari, R. M. Faulks, C. W. Kendall, G. T. Rich, M. S. Wickham, K. Lapsley and P. R. Ellis, Modelling of nutrient bioaccessibility in almond seeds based on the fracture properties of their cell walls, Food Funct., 2014, 5, 3096-3106. 